\title{
Development of a Safe Solid-State Microorganism/Biodegradable Polymer Composite for Decomposition of Formaldehyde
}

\author{
Ikuhiro Tanida $\cdot$ Asami Sakaue $\cdot$ Satoshi Osawa
}

Published online: 20 February 2014

(c) The Author(s) 2014. This article is published with open access at Springerlink.com

\begin{abstract}
A very safe and environmentally friendly solidstate material for bioremediation was prepared using a combination of Aspergillus oryzae and poly( $\varepsilon$-caprolactone) (PCL), a porous biodegradable polymer. The novel material was capable of decomposing 200 ppm formaldehyde solutions to 0 ppm within 7 days. Degradation ability was prolonged by addition of yeast extract-peptone-dextrose medium into the composite; $200 \mathrm{ppm}$ formaldehyde was decomposed to $0 \mathrm{ppm}$ over eight additional decomposition cycles and 100 days. A unique mechanism is proposed where, during PCL degradation, the solid-state composite provides nutrients to A. oryzae.
\end{abstract}

Keywords Aspergillus oryzae - Biodegradable polymer · Bioremediation · Formaldehyde $\cdot$ Poly( $\varepsilon$-caprolactone)

\section{Introduction}

Bioremediation has been employed in addressing a number of environmental problems, such as contaminated soil and groundwater, toxic industrial effluent, and poor air quality in living and working spaces [1-5]. Bioremediation is typically an efficient and low-cost environmental purification technique [6-8], and involves exploiting microorganism metabolism to remove pollutants. These technologies can be generally classified as in situ or ex situ. In situ bioremediation involves treating the contaminated material

I. Tanida $\cdot$ A. Sakaue $\cdot$ S. Osawa $(\bowtie)$

Department of Applied Chemistry, Kanazawa Institute of

Technology, 7-1 Ohgigaoka, Nonoichi, Ishikawa 921-8501, Japan

e-mail: osawa@neptune.kanazawa-it.ac.jp on-site, while ex situ involves the removal of the contaminated material for treatment elsewhere [9-11]. In both cases, the technology works by utilizing microorganism metabolism, and the microbes are usually released into rivers, lakes, soil and groundwater. It is imperative that the microbes utilized pose no threat to people at the contamination site or in the community. For this reason, confirmation of microorganism safety is required before carrying out bioremediation [12, 13].

The objective of this study was to produce a very safe and environmentally friendly solid-state material for use in bioremediation. This new type of material combines a safe microorganism and a biodegradable polymer, allowing for a wide range of potential applications, such as a filter or a component of purification systems for the decomposition or removal of harmful chemicals from industrial wastewater or tap water, as well as for treating poor air quality in our living spaces.

There are two types of microorganisms that are commonly known throughout the world to be very safe. One is the fungus Aspergillus oryzae, which has been used in Asian fermentation industries, such as the alcoholic beverage 'sake', the soybean paste 'miso', as well as for the production of soy sauce and vinegar for more than 1,000 years [14]. A. oryzae is also a widely used organism for the production of amylases, lipases and proteases, and has more recently been employed for the heterologous expression of secondary metabolite genes and non-fungal proteins [15-18]. The second group comprises lactobacilli and probiotic bacteria, which are frequently used as active ingredients in functional foods such as yogurts, dietary adjuncts and health-related products [17]. In previous studies [19, 20], we reported that A. oryzae produced various hydrolytic enzymes, including amylases and proteinases, that decompose biodegradable polymers such as poly( $\varepsilon$-caprolactone) (PCL) and 
poly(butylene succinate adipate) (PBSA), as well as harmful organic chemicals, e.g. formaldehyde, formic acid, tetrahydrofuran, and acrylamide. Moreover, the fungal filaments were observed to attach strongly to the microstructure of the biodegradable polymer surface. These features allow for the production of a solid-state microorganism/biodegradable polymer composite for use in bioremediation. PCL is a semicrystalline polymer with a glass transition temperature around $-60{ }^{\circ} \mathrm{C}$ and a melting temperature around $60{ }^{\circ} \mathrm{C}$. It is a ductile polymer and is, most often used in combination with different fillers [21].

In this study, we prepared an A. oryzae/PCL composite using an environmental friendly process. Formaldehyde was targeted for decomposition using the composite because it is widely used in industrial wood processing [22] and in the production of paper, leather, resins and glues
[23], and is a highly reactive compound, with toxic effects on living organisms through its nonspecific reactivity with proteins and nucleic acid. Decomposition capacity and sustainability of the composite for formaldehyde will be discussed in reference to its structure.

\section{Experimental}

Poly(E-caprolactone) (PCL; Daicel Chemical Co. Ltd., CELGREEN PH-7) $(\mathrm{Mn}=68,000, \mathrm{Mw}=125,000)$ was used for the preparation of the porous biodegradable polymer, with pore sizes ranging from 20 to $106 \mu \mathrm{m}$ and 20 to $60 \mathrm{vol} \%$ porosity. The value of porosity was calculated from the bulk density $\left(\rho_{\mathrm{b}}\right)$ and particle density $\left(\rho_{\mathrm{p}}\right)$ as follows:
Fig. 1 Schematic of the porous PCL sheet preparation process. Immobilization of $A$. oryzae spores $[I], A$. oryzae/porous PCL composite $[I I]$, germination of spores [III]
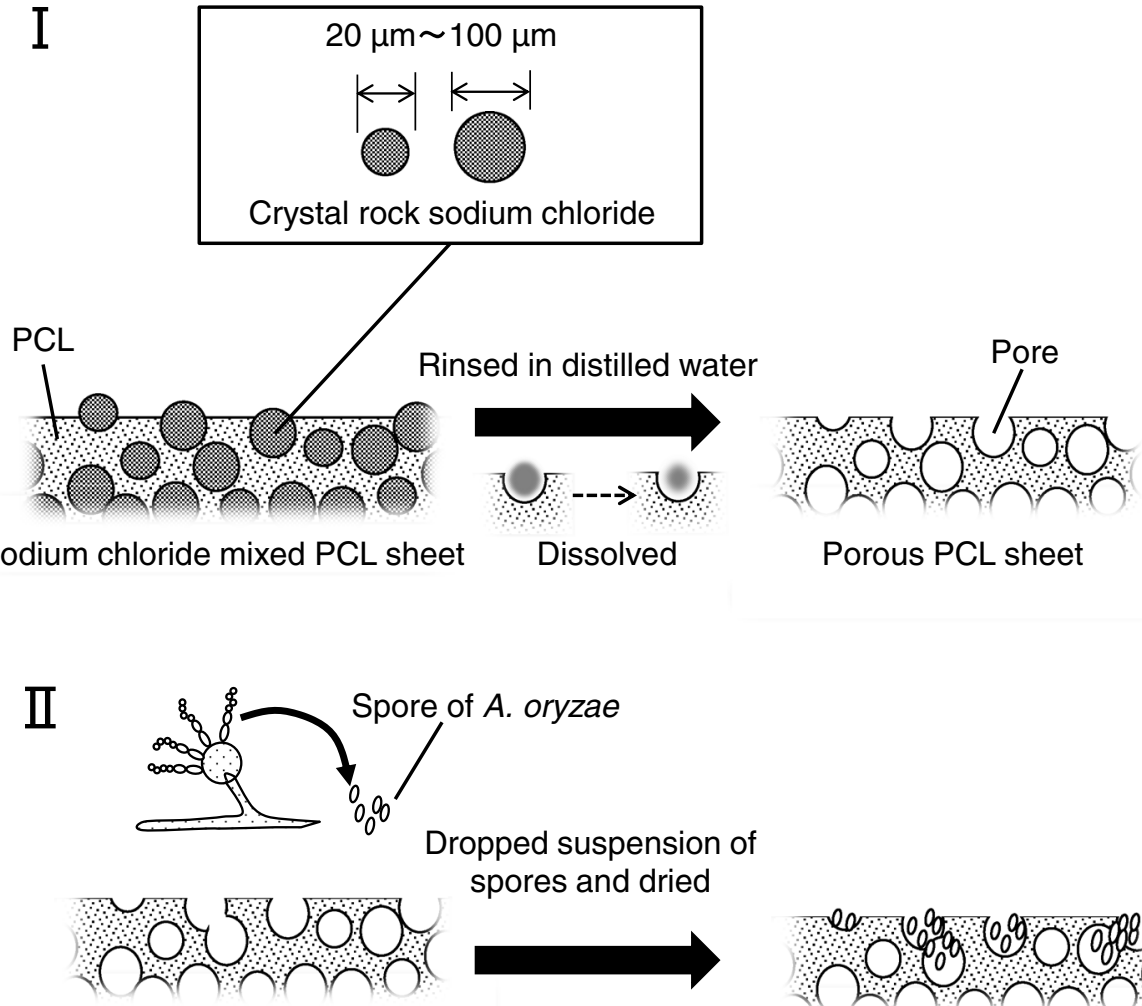

Porous PCL sheet

Porous PCL sheet

Spore of A. oryzae / Porous PCL
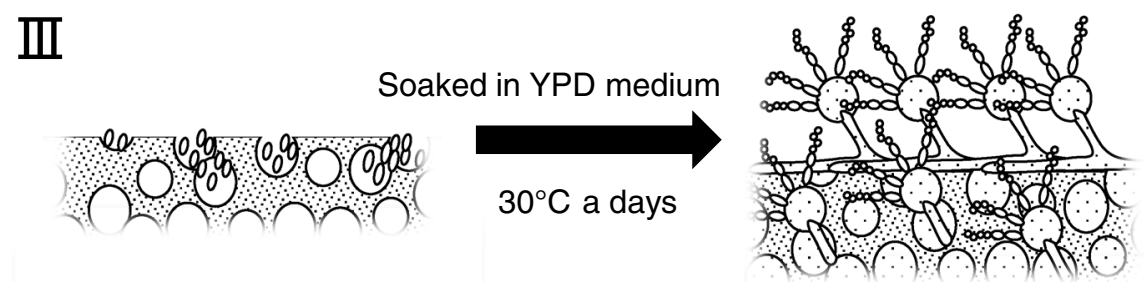

Spore of A. oryzae / Porous PCL

A. oryzae / Porous PCL sheet 
$\operatorname{Porosity}(\operatorname{vol} \%)=\left(1-\rho_{\mathrm{b}} / \rho_{\mathrm{p}}\right) \times 100$

Sodium chloride (solid) was pounded in a mortar, and the powder was screened through various sizes of mesh wire (20-106 $\mu \mathrm{m})$. The screened salt and PCL pellet were combined using a mixer (IMC-1A65; IMOTO Co. Ltd.) at $100{ }^{\circ} \mathrm{C}$ for $20 \mathrm{~min}$. The mixture was hot pressed at $120{ }^{\circ} \mathrm{C}$ for $5 \mathrm{~min}$ and rinsed with distilled water until the sample weight was to be constant. A. oryzae was incubated on PDA (Potato Dextrose Agar; Difco ${ }^{\mathrm{TM}}$ Becton Dickinson and Company) plates for a week at $30{ }^{\circ} \mathrm{C}$. The spores of $A$. oryzae were collected as a spore suspension by adding sterile water on the plate. Then the spore concentration was adjusted to $1 \times 10^{6}$ spores $/ \mathrm{mL}$. $500 \mu \mathrm{L}$ of the spore suspension was dropped on the porous PCL. Next, the porous PCL containing spores was dried under ambient conditions. Then, the spores on the PCL were germinated in YPD (yeast extract peptone dextrose; Difco ${ }^{\mathrm{TM}}$ YPD Broth, Becton Dickinson and Company) medium in shaking condition of $100 \mathrm{rpm}$. The process is shown in Fig. 1.

To obtain PCL sample containing nutrition, YPD powder $(40 \mathrm{wt} \%)$ and PCL pellets were combined at $80{ }^{\circ} \mathrm{C}$ using a mixer (IMC-1A65, Imoto Co. Ltd.) In order to enhance the attachment of $A$. oryzae fungal filaments, a micro-scale pattern was imprinted on the surface of the sheets by hot-pressing with $20 \mu \mathrm{m}$ wire mesh at $80{ }^{\circ} \mathrm{C}$. The composite containing YPD was also observed using scanning electron microscope (SEM).

The concentration of formaldehyde was measured by the Nash method [24] and HPLC (Separation Model 2695; Waters) using a column (CAPCELL PAK C8 type SG120, $5 \mu \mathrm{m}, 4.6 \mathrm{~mm}$ ID $\times 250 \mathrm{~mm}$ : Shiseido Co.). The flow rate and temperature were $1 \mathrm{~mL} / \mathrm{min}$ and $40{ }^{\circ} \mathrm{C} .0 .1 \%(\mathrm{v} / \mathrm{v})$ phosphate buffer was used as running buffer. The degradation tests were carried out in $50 \mathrm{~mL}$ of formaldehyde solution adding $500 \mathrm{mg}$ of $A$. oryzae /PCL composite with shaking (120 rpm) and static conditions.

\section{Results and Discussion}

Figure 2 shows SEM images of cross sections of nine PCL sheet samples with various pore sizes and porosity. It seems that the porosities of $40 \%$ indicated that most of pore connected each other. For the sample of porosity of

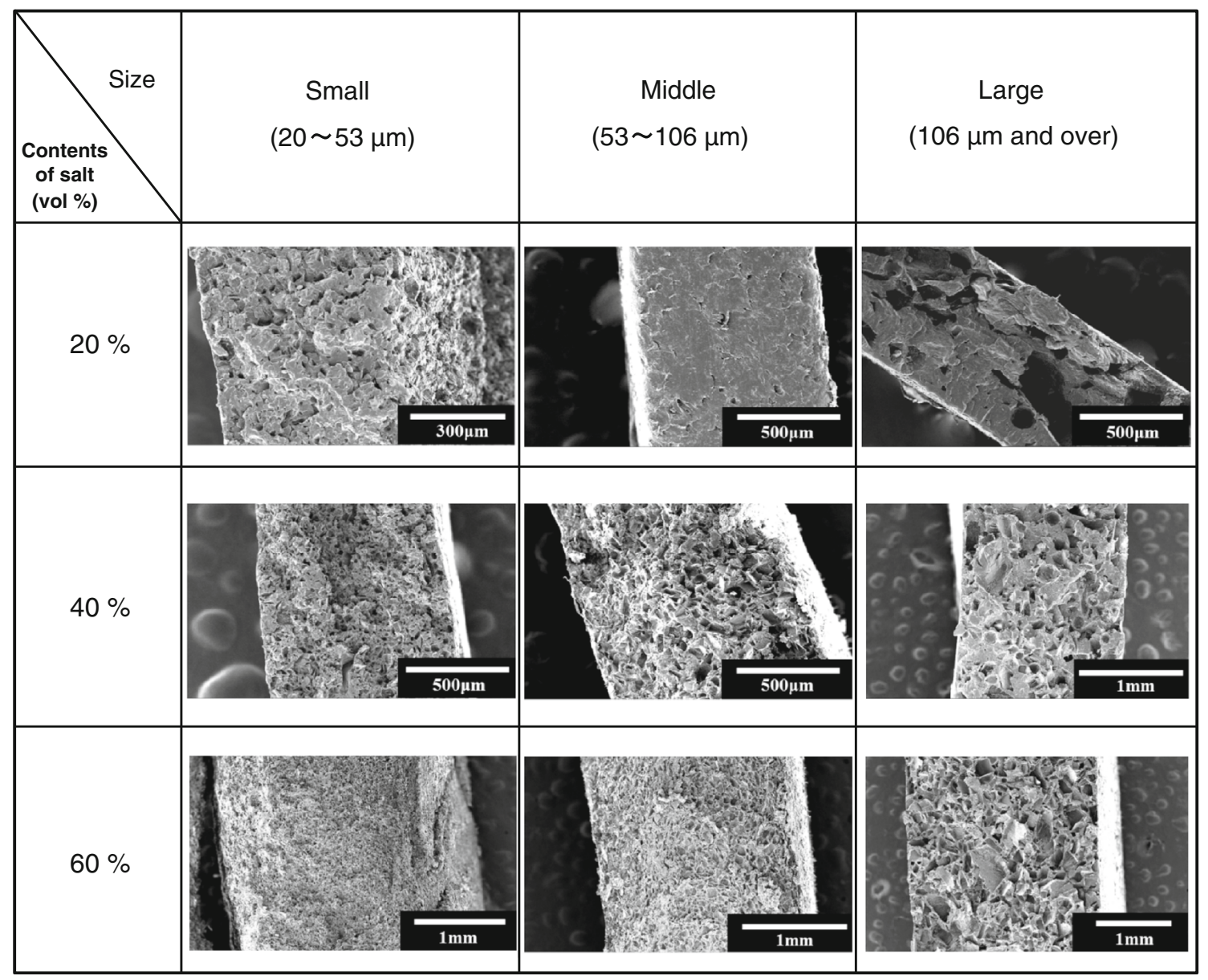

Fig. 2 SEM images of cross-sections of PCL sheets with various pore sizes and porosities 


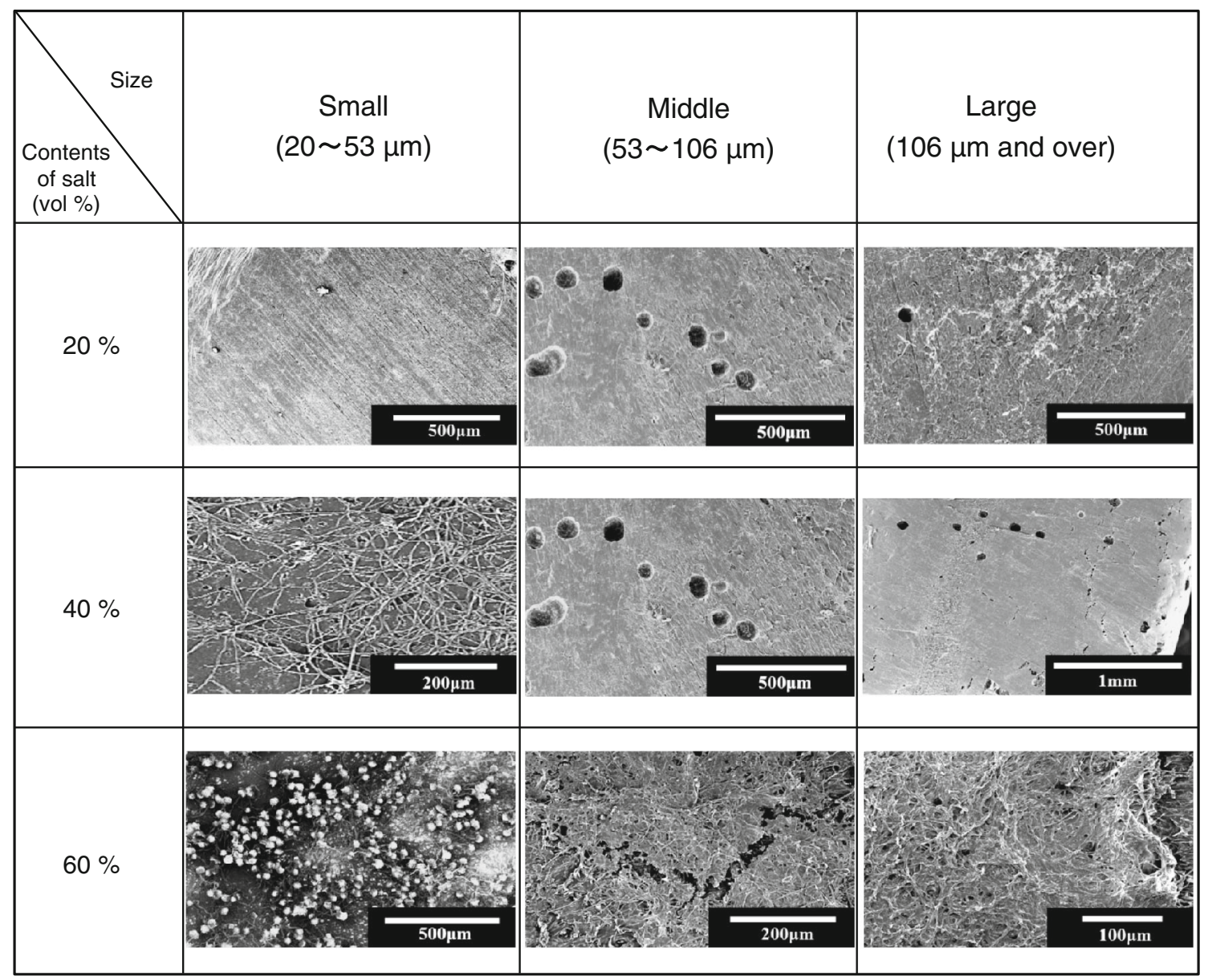

Fig. 3 SEM images of surface of A. oryzae/ PCL composite after spore germination. Spores were germinated in YPD medium under shaking condition for 1 day

$20 \%$, most of pores are not completely connected each other. Some of salts are isolated in the sample. Figure 3 shows SEM images of A. oryzael PCL composites after spore germination in YPD medium under shaking condition for 1 day. A large amount of $A$. oryzae obviously adhered to the samples with $20-53 \mu \mathrm{m}$ pore size and with 40 and $60 \%$ porosities, and filament growth and spore production was observed. Table 1 provides the amounts of $A$. oryzae immobilized on the nine PCL samples under shaking and static incubation conditions for one day. The porous PCL with $20-53 \mu \mathrm{m}$ pore size and $60 \%$ porosity was suitable for immobilization of $A$. oryzae filaments.

Figure 4 shows the capacity of $A$. oryzae/PCL composites to degrade formaldehyde at $30{ }^{\circ} \mathrm{C}$. The composites $(500 \mathrm{mg}$ pieces) were added to $50 \mathrm{~mL}$ of $200 \mathrm{ppm}$ formaldehyde solution. The decomposition rate depended on the material's porosity and on the incubation conditions. The $60 \%$ porosity sample with shaking exhibited the highest degradation rate of formaldehyde and completely decomposed it within 5-7 days. When A. oryzae alone was added to formaldehyde, the concentration did not decrease over the 12 days, clearly indicating that $A$. oryzae attachment to the PCL composite is important for its effectiveness [25-27]. In general, spores showed high germination and attached strongly to the solid scaffolds [27], as shown in Fig. 3. It was observed that degradation ability continued when the composite was exposed to a second $200 \mathrm{ppm}$ formaldehyde solution, although the degradation rate was lower than upon initial exposure. The results indicate that this novel material is useful for the purification of formaldehyde dissolved in water.

Previously, it has been reported that $400 \mathrm{ppm}$ of formaldehyde has been degraded by bacterium [28]. However, we were considering that bacterium couldn't very well adhere to the matrix. The organisms grows attached to the matrix is a needful methods when make use of it for the environmental.

It is a known fact [29], that the formaldehyde is degraded by Aspergillus flavus. In this regard, since it is an unsafe organism, compared with existing the method by $A$. 
Table 1 Amounts of A. oryzae immobilized on $500 \mathrm{mg}$ samples of porous PCL

\begin{tabular}{|c|c|c|c|}
\hline \multicolumn{2}{|l|}{ Samples } & \multicolumn{2}{|c|}{ A. oryzae (mg dry weight) } \\
\hline $\begin{array}{l}\text { Pore size } \\
(\mu \mathrm{m})\end{array}$ & $\begin{array}{l}\text { Porosity } \\
\text { (vol\%) }\end{array}$ & $\begin{array}{l}\text { Without } \\
\text { shaking }\end{array}$ & $\begin{array}{l}\text { Shaking } \\
\text { (150 rpm) }\end{array}$ \\
\hline $20-53$ & 20 & 0.7 & 0.2 \\
\hline $20-53$ & 40 & 3.3 & 0.7 \\
\hline $20-53$ & 60 & 3.5 & 0.6 \\
\hline $53-106$ & 20 & - & - \\
\hline $53-106$ & 40 & 0.8 & 0.2 \\
\hline $53-106$ & 60 & 0.6 & 0.2 \\
\hline$>106$ & 20 & 0.2 & - \\
\hline$>106$ & 40 & 0.1 & - \\
\hline$>106$ & 60 & 0.6 & 0.1 \\
\hline
\end{tabular}

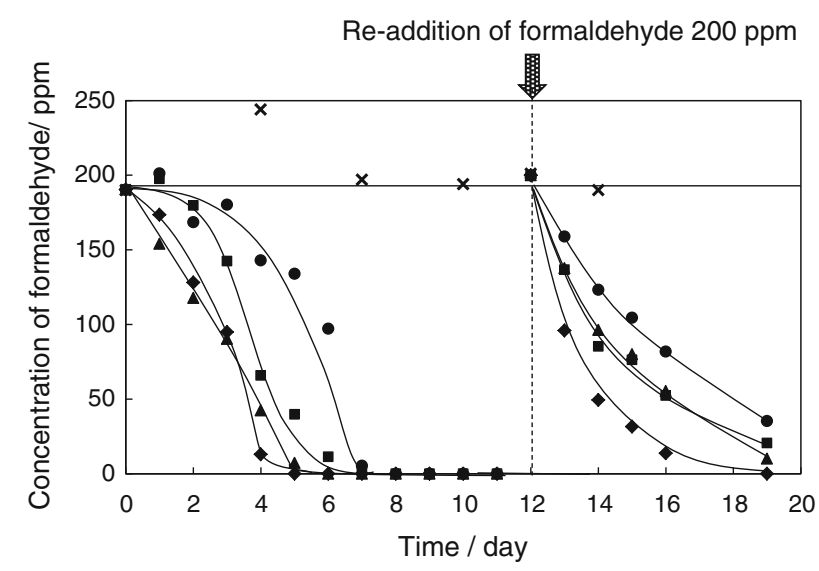

Fig. 4 Ability of A. oryzae/PCL composites to degrade formaldehyde. $40 \%$ porosity in shaking culture (filled circle), $40 \%$ porosity in static culture (filled triangle), $60 \%$ porosity in shaking culture (filled square), $60 \%$ porosity in static culture (filled diamond), control ( $\times$; A. oryzae alone)

flavus, this method allowed safe bioremediation use of $A$. oryzae.

Sterilized A. oryzae never decompose formaldehyde under the same condition of Fig. 4. Therefor A. oryzae still grow even for long time after 100 days. The results clearly show that the composite materials slowly deliver the nutrients to A. oryzae, successfully.

TOF-MS analysis of the enzyme produced by A. oryzae produce an enzyme to be assigned to a SOD oxidation enzyme under the same condition of our prior study by using of TOF-MS analysis, the enzyme might be oxidize formaldehyde [30].

Two strategies were employed in an attempt to further improve the process: increasing the sustainability of degradation and enhancing the degradation rate. The first strategy

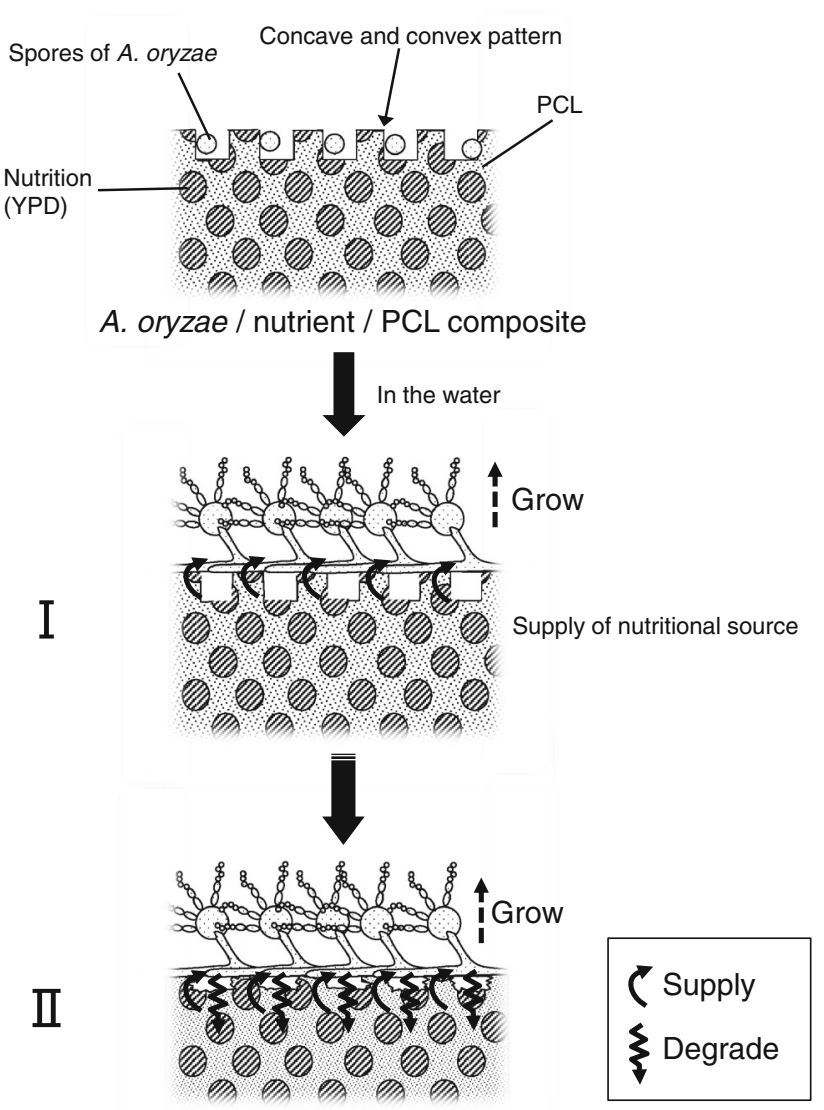

Degrade a Poly ( $\varepsilon$-caprolactone) and get more of nutritional source

Fig. 5 Schematic of $A$. oryzae/nutrient/PCL composite preparation. A. oryzae spores germinate and grow on the PCL composite $[I]$, and nutrients are supplied to $A$. oryzae during degradation of the nutrientcontaining PCL composite $[I I]$

involved the gradual and continuous supply of nutrients to $A$. oryzae. For this purpose, we prepared a PCL composite containing $A$. oryzae spores and YPD medium. The second strategy involved A. oryzae growth enhancement on the composite by making concave and convex patterns on the surface, thereby promoting A. oryzae germination and attachment. We previously reported that the fungus grew and the filaments attached strongly to the $20-\mu \mathrm{m}$ mesh pattern imprinted of the PCL surface [31]. The micro-pattern would enhance the A. oryzae attachment on the surface, leading to enhance rate of formaldehyde degradation.

Figure 5 shows a schematic of composite production using the above-mentioned two strategies. In the first step, A. oryzae spores germinate and grow on the PCL. In the second step, the surface-attached $A$. oryzae begins to degrade the PCL. As a result, nutrients are released from the YPD medium within the PCL and supplied to A. ory$z a e$. This process continues until the composite is completely degraded, allowing for continued decomposition of formaldehyde. 


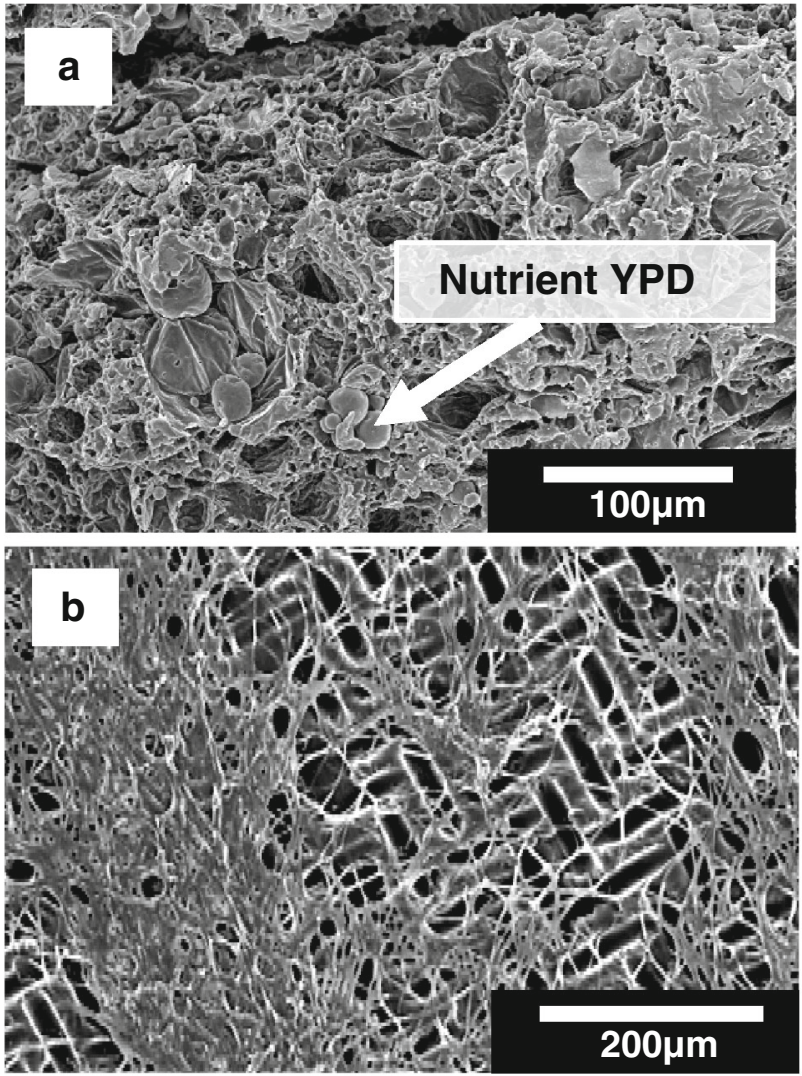

Fig. 6 SEM images of the composite containing YPD powder and imprinted with a mesh micro-pattern. Cross-section (a), surface (b) images

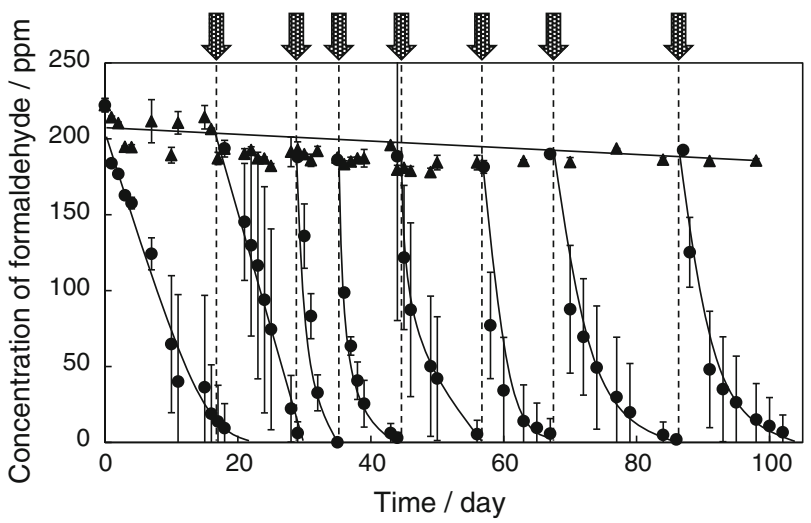

聞 Re-addition to 200 ppm formaldehyde solution

Fig. 7 Sustainability of A. oryzae/nutrient/PCL composite (filled circle) or A. oryzae (filled triangle) formaldehyde degradation

Figure 6 shows SEM images (cross-section and surface) of the composite containing $40 \mathrm{wt} \%$ nutrient YPD powder and imprinted with a mesh micro-pattern on the surface. The YPD is partially isolated in the PCL sheets (cross- section). A. oryzae filaments grew on the material's surface, covering the composite (surface). The composite has potential for decomposing formaldehyde or other chemicals using enzymes produced by the surface-attached $A$. oryzae.

The sustainability of formaldehyde degradation by the composite containing YPD is shown in Fig. 7. During the first addition/degradation cycle, the composite reduced $200 \mathrm{ppm}$ formaldehyde to $0 \mathrm{ppm}$ within 18 days; a degradation rate much lower than for the $A$. oryzae/porous PCL composite (6 days) shown in Fig. 4. In contrast, during the second addition/ degradation cycle, the degradation rate increased and was nearly the same as for the $A$. oryzae/PCL composite. Formaldehyde degradation was maintained over eight addition/degradation cycles and 100 days. The results show the composite supplied nutrients to the surface-attached $A$. oryzae, allowing for $A$. oryzae to decompose the formaldehyde. We have reported that $A$. oryzae hydrolyzes PCL and assimilates 6-hydroxyl hexanoic acid. During PCL degradation, the composite supplies sufficient nutrients to A. oryzae, leading to high sustainability of formaldehyde degradation.

\section{Conclusion}

We prepared a very safe and environmentally friendly solid-state material for use in bioremediation, by combining A. oryzae, a microorganism known to be safe, and a porous biodegradable PCL polymer. The composite showed a high capacity for decomposing formaldehyde solution. Degradation was strongly improved by the addition of a nutrient medium (YPD) to the composite. The mechanism by which the $A$. oryzae/nutrient/biodegradable polymer composite undergoes degradation and continues to supply nutrients to $A$. oryzae is useful for long-term formaldehyde decomposition.

Acknowledgments We appreciate the financial support from Grants-in-Aid for Scientific Research No. 23510113 and Ministry of Education, Culture, Sports, Science and Technology-Supported Program for the Strategic Research Foundation at Private Universities in Japan, 2009-2013.

Open Access This article is distributed under the terms of the Creative Commons Attribution License which permits any use, distribution, and reproduction in any medium, provided the original author(s) and the source are credited.

\section{References}

1. Zhongun X, Haiping H (2010) Formaldehyde removal from air by a biodegradation system. Bull Environ Contam Toxicol $85: 28-31$ 
2. Curling SF, Loxton C, Ormondroyd GA (2012) A rapid method for investigating the absorption of formaldehyde from air by wool. J Mater Sci 47:3248-3251

3. Chiristov L, van Driessel B (2003) Waste water bioremediation in the pulp and paper industry. Indian J Biotechnol 2:444-450

4. Vara S, Maruthi YA, Mukkanti K (2010) Potential fungi for bioremediation of industrial effluents. BioResoures 5:8-9

5. Boopathy R (2000) Factors limiting bioremediation technologies. Bioresour Technol 74:63-67

6. Tyagi M, da Fonsce MMR, de Carvalho CCCR (2011) Bioaugmentation and biostimulation strategies to improve the effectiveness of bioremediation processes. Biodegradation 22:231-241

7. Rivelli Y, Franzetti A, Gandolfi I, Cordoni S, Bestetti G (2013) Persistence and degrading activity of free and immobilised allochthonous bacteria during bioremediation of hydrocarbon-contaminated soils. Biodegradation 24:1-11

8. Lee E-H, Tsujimoto T, Uyama H, Sung M-H, Kwang Kim, Kuramitsu S (2010) Enhancement of enzyme activity and stability by poly ( $\gamma$-glutamic acid). Polym J 42:818-822

9. Chowdhury S, Bala NN, Dhauria P (2012) Bioremediation-a natural way for cleaner environment. IJPCBS 2:600-611

10. Baker AJM, Brooks RR (1989) Terrestrial higher plants which hyperaccumulate metal elements: a review of their distribution, ecology, and phytochemistry. Biorecovery 1:81-126

11. Sharma S (2012) Bioremediation: features, strategies and applications. AJPLS 2:202-213

12. U.S. Environmental Protection Agency (2012) A citizen's guide to bioremediation: EPA 542-F-01-001

13. Vidali M (2001) Bioremediation. An overview. Pure Appl Chem 73:1163-1172

14. Machida M, Terabayashi Y, Sano M, Yamae N, Tamano K, Payne GA, Yu J, Cleveland TE, Nierman WC (2008) Genomics of industrial Aspergilli and comparison with toxigenic relatives. Food Add Contam 25:1147-1151

15. Rank C, Klejnstrup ML, Petersen LM, Kildgaard S, Frisvad JC, Gotfredsen CH, Larsen TO (2012) Comparative chemistry of Aspergillus oryzae (RIB40) and A. flavus (NRRL 3357). Metabolites 2:39-56

16. Punt PJ, Biezen NV, Conesa A, Albers A, Mangnus J, van den Hondel C (2002) Filamentous fungi as cell factories for heterologous protein production. Trends Biotechnol 20:200-206

17. Meyer V (2008) Genetic engineering of filamentous fungi-progress, obstacles and future trends. Biotechnol Adv 26:177-185

18. Fisch KM, Bakeer W, Yakasai AA, Song Z, Pedrick J, Wasil Z, Bailey AM, Lazarus CM, Simpson TJ, Cox RJ (2011) Rational domain swaps decipher programming in fungal highly reducing polyketide synthases and resurrect an extinct metabolite. J Am Chem Soc 133:16335-16641

19. Mizuno K, Ohashi S, Osawa S (2007) Enzymatic degradation of poly(butylene succinate-co-adipate) with subsequent degradations of the decomposed monomers by filamentous fungi. Kobunshi Ronbunshu 64:786-790

20. Osawa S, Mizuno K, Kido H (2007) A enzymatic degradation of poly( $\varepsilon$-caprolactone) and subsequent degradation of the low molecular weight component by filamentous fungi. Mat Technol 25:170-174

21. Lönnberg H, Hult A, Malmström E (2010) Grafting of polycaprolactone from microfibrillated cellulose and the investigation of graft lengths impact on the mechanical properties in nano-biocomposites. Publications from Norwegian University of Science and Technology, pp 1-19

22. Glancer-Šoljan M, Šoljan V, Dragičevi TL, Čačić L (2001) Aerobic degradation of formaldehyde in wastewater. Food Technol Biotechnol 39:197-202

23. Kirk RE, Othmer DF (1980) Encyclopedia of chemical technology. Wiley, New York, pp 236-250

24. Nash T (1953) The colorimetric estimation of formaldehyde by means of the Hantzsch reaction. Biochem J 55:416-421

25. Dubin HJ, Mccarty PL (2000) Impact of colony morphologies and disinfection on biological clogging in porous media. Environ Sci Technol 34:1513-1520

26. Nikolajeva V, Griba T, Petrina Z (2012) Factors influencing adhesion of Pseudomonas putida on porous clay ceramic granules. Environ Exp Biol 10:77-80

27. Sanin S (2004) Effect of surface properties and flow regime on the transport of bacteria in groundwater: an experimental approach. Turkish J Eng Env Sci 28:317-324

28. Yamazaki T, Tsugawa W, Sode K (2001) Biodegradation of formaldehyde by a formaldehyde-resistant bacterium isolated from seawater. Appl Biochem Biotechnol 91-93:213-217

29. Yanagita T (1980) Studies on the formaldehyde resistance of Aspergillus fungi attacking the silkworm larvae. J Sericult Sci 49:45-50

30. Tanida I, Moriguchi Y, Narita T, Ohashi S, Osawa S (2010) Degradation of formaldehyde and formic acid by A. oryzae immobilized on a micro-patterned surface of a biodegradable polymer. Kobunshi Ronbunshu 70:502-509

31. Osawa S, Tanida I, Narita T (2010) Microbial adhesion behavior on the micro-structural surface of biodegradable polymer. Kobunshi Ronbunshu 67:104-109 